\title{
ATENÇÃO DA EQUIPE DE ENFERMAGEM DURANTE O PRÉ-NATAL: PERCEPÇÃO DAS GESTANTES ATENDIDAS NA REDE BÁSICA DE ITAPURANGA - GO EM DIFERENTES CONTEXTOS SOCIAIS
}

\author{
NURSING TEAM ATTENTION DURING PRENATAL: \\ PERCEPTION OF PREGNANT WOMEN ASSISTED IN BASIC NETWORK \\ AT ITAPURANGA - GO IN DIFFERENT SOCIAL CONTEXTS
}

\author{
Ana Claudia Rocha', Gislângela Silva Andrade ${ }^{2}$ \\ Autora para correspondência: Ana Claudia Rocha - ana.clrocha@hotmail.com \\ 'Licenciada em História. Pós-graduanda em Docência: Interdisciplinaridades e Demandas Contemporâneas \\ pela Universidade Estadual de Goiás. Anápolis, Goiás, Brasil. \\ ${ }^{2}$ Enfermeira. Pós-graduanda em Enfermagem em Ginecologia e Obstetrícia e Saúde Pública. \\ Docente na Universidade Estadual de Goiás. Anápolis, Goiás, Brasil.
}

RESUMO I O pré-natal tem como objetivo principal - acompanhamento à gestante, se caracterizando em um momento de aprendizado para gestante e sua família. Essa assistência deve ser realizada por profissional habilitado e capacitado que dê suporte a gestante durante o pré-natal. Sendo assim é neste contexto que se destaca o enfermeiro, que tem como meta $\circ$ acolhimento das gestantes na unidade de saúde, com o propósito de sanar dúvidas e medos relacionados ao momento vivenciado por elas. A pesquisa teve como objetivo de conhecer e avaliar a assistência de enfermagem prestada a gestantes em três ESF's localizada no município de ltapuranga-GO, partindo da percepção das mesmas. Foi realizado um estudo observacional, transversal e qualiquantitativo sobre a assistência de enfermagem prestada a gestantes de baixo risco em contexto social diferente em Itapuranga - GO por meio de um questionário misto com perguntas objetivas e subjetivas. Resultados: das 30 gestantes entrevistadas nas três ESF's, 90\% estão satisfeitas com a consulta de enfermagem e $10 \%$ parcialmente satisfeitas. No entanto constatamos que $\circ$ atendimento nas consultas são padronizadas ocorrendo do mesmo modo. Concluímos que o trabalho do enfermeiro no pré-natal ainda enfrenta barreiras, no entanto, o impacto positivo de suas ações bem como o reconhecimento do seu trabalho é evidente e destacado pelas gestantes.

Palavras-chave: Pré-natal, Assistência de Enfermagem, Estratégia Saúde da Família

\begin{abstract}
Prenatal care has as main objective the accompaniment to the pregnant woman, being characterized in a moment of learning for pregnant women and their family. This assistance must be performed by a skilled and trained professional who supports pregnant women during prenatal care. Therefore, it is in this context that the nurse stands out, whose goal is the reception of pregnant women in the health unit, with the purpose of healing doubts and fears related to the moment experienced by them. The objective of the research was to know and evaluate the nursing care provided to pregnant women in three FHSs located in the city of Itapuranga-GO, based on their perception. An observational, transversal and qualitauantitative study on nursing care provided to low - risk pregnant women in a different social context was carried out in ltapuranga - GO through a mixed questionnaire with objective and subjective questions. Results: Of the 30 pregnant women interviewed in the three $\mathrm{FHS}, 90 \%$ were satisfied with the nursing visit and $10 \%$ were partially satisfied. However we verify that the attendance in the consultations are standardized occurring in the same way. We conclude that nurses' work in prenatal care still faces barriers, however, the positive impact of their actions as well as the recognition of their work is evident and highlighted by pregnant women.
\end{abstract}

Key words: Prenatal care, Nursing care, Family Health Strategy. 


\section{INTRODUÇÃO}

O pré-natal é o acompanhamento voltado as gestantes. Conceituado como um conjunto de ações que antecedem ao parto, tendo por finalidade atender as necessidades da mulher, promovendo a qualidade de vida e prevenido intercorrências'.

A gestação marca uma fase de mudanças na vida e no corpo da mulher. Essas modificações além de físicas e emocionais são também sociais, sexuais e afetivas gerando sensações mistas de prazer, alegria, medo, ansiedade e angustia. Portanto o pré-natal pode ser considerado um período de preparação tanto biológica quanto psicológica para o parto e posteriormente para a maternidade. Sendo este momento de vasto aprendizado, onde a mulher pode sanar dúvidas, sendo de fundamental importância para o desenvolvimento do binômio mãe-filho².

A assistência ao pré-natal tem como objetivo o acolhimento da gestante desde o diagnóstico da gestação, visando acolher a mulher em um momento de transição e modificações físicas e emocionais de forma individualizada. Para o Ministério da Saúde $(2006)^{4}$, o acolhimento é um aspecto essencial da política de humanização, resulta na recepção da mulher, desde sua chegada à unidade básica, onde os profissionais de saúde se responsabilizam por ela, ouvindo suas queixas e permitindo que ela expresse suas preocupações, angustias, garantindo atenção primordial e articulando com outros serviços de saúde, fornecendo dessa maneira continuidade a assistência, quando necessário.

O pré-natal tem contribuído de forma notável para a saúde pública, diminuindo o risco de complicações tanto no pré-natal quanto no pós-parto, através de consultas periódicas com enfermeiros. As consultas de enfermagem são baseadas nos conceitos de prevenção, promoção e vigilância da saúde, que visa garantir o bem-estar e melhor qualidade de vida para as gestantes ${ }^{3}$.

Para o MS $(2006)^{4}$, as gestantes estão buscando - pré-natal devido à qualidade da assistência prestada pelo serviço e profissionais de saúde, uma vez que elas estão cada dia mais consciente da importância deste atendimento para a diminuição dos elevados índices de mortalidade materno-fetal. Diante disso é importante ressaltar que o SUS preconiza dentre seus princípios e diretrizes a integralidade da assistência que é entendida como conjunto articulado e continuo das ações, serviços preventivos e curativos, individuais e coletivos, exigido para cada caso em todos os níveis de complexidade do sistema, e a integralidade na assistência depende primordialmente de quem a pratica, neste caso, o enfermeiro ${ }^{5}$.

Desta forma vai depender do enfermeiro que a consulta tenha nuances diferentes, para atender as expectativas da paciente, fazendo com que aconteça uma relação de confiança e troca entre - profissional e paciente, preconizando uma assistência de qualidade humanitária ${ }^{6}$.

Atualmente, a consulta de enfermagem na rede básica de saúde é realizada de acordo com roteiro estabelecido pelo MS, garantida pela Lei do Exercício Profissional e o Decreto n 94.406/874.

Este trabalho se justifica pelo fato do pré-natal ser - acompanhamento e acolhimento que a gestante recebe, a fim de proporcionar promoção, prevenção e tratamento de possíveis intercorrências durante o período gestacional e pós-parto, além de preparar a gestante para um puerpério saudável e tranquilo. O enfermeiro desempenha um papel de extrema importância, para que ocorra um pré-natal de qualidade já que a equipe de enfermagem deve estar apta a realizar uma assistência humanizada, baseada na atenção às queixas da paciente, executando e prescrevendo cuidados, orientações de qualidade durante $\mathrm{O}$ atendimento. $\mathrm{Na}$ consulta de pré-natal o enfermeiro e sua equipe desenvolvem assistência integral a gestante por meio de ações e procedimentos técnicos e científicos, assegurando uma gestação sem intercorrências ou minimizando os agravos/desconfortos que podem surgir no decorrer da gestação.

Durante a gestação a mulher passa por mudanças anatômicas, fisiológicas e psicológicas. O pré-natal é um momento em que a mulher tem para conhecer e compreender as mudanças que estão ocorrendo em seu corpo, à equipe de enfermagem utilizando- 
se de ações e atividades educativas como forma de sanar dúvidas em relação a uma alimentação saudável, preparar as gestantes para realização de cuidados com o recém-nascido, e a importância do aleitamento materno, promove dessa maneira uma gestação e puerpério tranquilo. Contudo a equipe de enfermagem da rede básica de saúde necessita estar apta com conhecimentos técnicos, científicos e humanizados para trabalhar temas relevantes a essa etapa tão especial na vida da mulher, sendo de extrema importância que a gestante faça o acompanhamento de sua gestação.

Temos por objetivo conhecer e avaliar a assistência de enfermagem prestada a gestantes em três ESF's localizadas respectivamente na periferia, central e rural do município de Itapuranga - GO, durante o pré-natal de baixo risco, a partir da percepção das gestantes. Os resultados obtidos no estudo serão divulgados no trabalho de conclusão de curso da Graduação de Enfermagem da Universidade Estadual de Goiás, e será confeccionado artigo científico e enviado para publicação. Os resultados serão repassados para o secretário de saúde e a coordenadora dos ESF's do município de ltapuranga - GO.

\section{DESENVOLVIMENTO}

O processo de criação do Sistema Único de Saúde (SUS) teve inicio nos pressupostos legais estabelecidos pela Constituição Federal de 1988: "A saúde é direito de todos e dever do Estado", e da Lei Orgânica de Saúde, Lei número 8.080 e Lei número 8.142 , que tem a finalidade de acabar ou minimizar a desigualdade na assistência à saúde prestada a população, tornando assim $\circ$ atendimento público obrigatório para qualquer cidadão, sem cobrança de qualquer taxa ou valor, nas quais destacou os princípios organizativos e operacionais do sistema, como a construção do modelo de atenção fundamentado na epidemiologia, no controle social e em um sistema descentralizado e regionalizado com base municipal?

A efetivação do SUS ocasionou na mudança do modelo assistencial centrado na doença, dando ênfase para a atenção primária a saúde ${ }^{8}$.

Os municípios passaram a ser os principais responsáveis pela coordenação e execuções de ações e serviços de saúde, surgindo assim o Programa Saúde da Família (PSF) (1970), cuja chamada medicina familiar fazia parte do currículo da medicina, e tinha um único objetivo: a "necessidade de humanizar a medicina". Em 1979, a Assembleia Mundial de Saúde definiu o conceito de atenção primária à saúde e dentro dele destacou a questão da família ${ }^{7}$.

Em 1994, o modelo assistencial a saúde passou por uma reorganização, onde foi criado o Programa Saúde da Família (PSF), que atualmente é denominado Estratégia de Saúde da Família (ESF), pautado nos princípios da integralidade, da vigilância a saúde, da equidade, centrada no acolhimento, prevenção à saúde e na humanização. Para efetivar o modelo assistencial, a ESF deve ter como descrições básicas de proposta de modelo de assistência à constituição de uma rede hierarquizada e complementar de atenção à saúde, o caráter multiprofissional das equipes de trabalho, a utilização de informação epidemiológica para - planejamento e a programação de saúde, e a busca de concretização da integridade das práticas na atenção à saúde?

O programa é organizado em parceria com as Secretarias Estaduais e Municipais de Saúde, e Instituições de Ensino Superior que juntos tentam atingir prioritariamente populações mais carentes da sociedade. O seu funcionamento é por meio de uma Unidade de Saúde da Família, com uma equipe multiprofissional composta por um médico, um enfermeiro, um auxiliar ou técnico de enfermagem e agentes comunitários de saúde ${ }^{10}$.

O atendimento ao pré-natal consiste em um dos principais indicadores do Pacto da Atenção Básica do SUS, sendo que a assistência realizada envolve toda uma série de procedimentos que os serviços devem realizar para outras ações de atenção básica ${ }^{11}$.

Visando melhorar a atenção obstétrica e a redução das altas taxas de morbimortalidade materna, - Ministério da Saúde elaborou no ano de 2000, - Programa de Humanização no Pré-Natal e 
Nascimento (PHPN), que traz em seu modelo assistencialista o paradigma da humanização, como modelo de atenção a mulher durante a gestação e o parto. Tendo como características e principais estratégias o acesso à saúde, cobertura e qualidade no acompanhamento do pré-natal, assistência ao parto e puerpério. A humanização abrange dois pontos fundamentais: primeiro: é dever das instituições de saúde receber, acolher com dignidade a mulher, seus familiares e o recém-nascido. Os profissionais devem adotar atitude ética, solidaria e humanizada. Desta forma proporcionando um ambiente acolhedor. $O$ segundo: refere à implementação de medidas e procedimentos benéficos para o acompanhamento do parto e nascimento, evitando intervenções desnecessárias ${ }^{12}$.

Dessa forma o Ministério da Saúde estabeleceu diretrizes para atenção pré-natal, dentre ela destacam: rotinas preconizadas para consultas, fatores de risco na gestação, forma de ampliar a assistência, incluindo normas, participação da equipe de enfermagem como membro da equipe que presta cuidados a mulher durante $\circ$ ciclo gravídico-puerperal, que é legalizado pelo Decreto $n^{\circ} 94.406 / 87$.

De acordo com o Ministério da Saúde $(2012)^{13}$, para a realização de um pré-natal de qualidade é necessário um conjunto de recursos que compreende: recursos humanos, área física adequada, equipamentos e instrumentos mínimos, apoio laboratorial, material para registro, processamento, analise de dados e medicamentos. Porém somente isso não garante que o pré-natal seja bem sucedido, para ter qualidade além desses recursos físicos é necessário um relacionamento de confiança entre profissionais, a gestante e a família.

COSTA et al (2009) $)^{14}$, salienta que a gestante é o foco do pré-natal, porém é necessário incluir a família nesse momento impar de sua vida, o acompanhante transmite segurança e confiança para a gestante. Conforme destaca também o MS (2006)4, é um direito da gestante o acompanhamento de alguém da família, amigo, ou doula, durante as consultas de pré-natal, trabalho de parto, parto e pós-parto esse direito é regulamentado pela Lei $n^{\circ} 11.108$, de sete de abril de 2005.
Diante do exposto percebemos a necessidade de assistir e acompanhar a mulher do início do período gestacional ao seu término, possibilitando avaliar as condições maternas e fetais, prevenindo, amenizando ou até mesmo intervindo nas possíveis complicações materno-fetais ${ }^{15}$.

O diagnóstico de gravidez é baseado na anamnese detalhada, no exame físico e teste laboratorial. Para detectar a gravidez, o Ministério da Saúde, por intermédio da Rede Cegonha incluiu o Teste Rápido de Gravidez nos exames de rotina do pré-natal, que pode ser realizado na unidade de saúde, o que contribui para acelerar o processo de confirmação da gravidez, iniciando imediatamente o acompanhamento do pré-natal ${ }^{13}$.

Após o diagnóstico positivo para gravidez inicia o acompanhamento, é realizado o cadastrado da gestante no SisPré-Natal, preenchimento do cartão da gestante, verificação do cartão de vacina (imunização contra tétano e Hepatite B), solicitação de exames laboratoriais preconizados na primeira consulta: hemograma para verificar dosagem de hemoglobina e hematócrito $(\mathrm{Hb} / \mathrm{Ht})$; grupo sanguíneo e o fator $\mathrm{Rh}$; glicemia em jejum, exame sumário de urina (EAS tipo I): repetir todos próximo a $30^{a}$ semana. O Teste da Mamãe, foi implantado em setembro de 2003, são feitas triagem para sífilis, HIV/Aids, toxoplasmose, rubéola, doença de Chagas, hepatite $B$ e $C$ e de citomegalovírus e HTLV, na primeira amostra, a segunda amostra é feita por volta da $30^{\circ}$ semana e é realizada triagem apenas para sífilis e HIV/Aids ${ }^{13}$.

Neste contexto, a Associação de Pais e Amigos Excepcionais (APAE-Goiânia), em convênio com a Secretaria Estadual e com as Secretarias Municipais de Saúde de Goiás, desenvolveu um programa de triagem pré-natal para investigação de doenças que podem ser transmissíveis durante a gravidez e causar sequelas na criança $^{16}$.

O exame físico deverá ser completo, constando avaliação de cabeça e pescoço, tórax, abdômen, membros e inspeção de pele e mucosas, seguidas por exame ginecológico e obstétrico ${ }^{2}$.

Nas próximas consultas, a anamnese deverá ser suscinta, focada em aspectos do bem-estar 
materno e fetal. Inicialmente deverão ser ouvidas dúvidas e ansiedades da mulher, depois questionála sobre alimentação, hábito intestinal e urinário, movimentação fetal e interrogá-la sobre a presença de corrimentos ou outras perdas vaginais. As anotações devem ser realizadas tanto no prontuário da unidade quanto no cartão da gestante ${ }^{5}$.

Para um acompanhamento pré-natal de qualidade, é necessário que a equipe de saúde realize correta e uniformemente os procedimentos técnicos durante o exame clinico e obstétrico. Do contrário, ocorrerão diferenças significativas, prejudicando a comparação e a interpretação dos dados ${ }^{17}$.

De acordo com o Ministério da Saúde, um pré-natal ideal deve ter no mínimo seis consultas, devendo iniciar no primeiro trimestre, duas no segundo e três no terceiro trimestre de gestação. Os intervalos entre consultas devem ser de quatro semanas até que complete 36 semanas. Após os intervalos são de 15 dias. Em casos de gestantes faltosas a equipe de enfermagem juntamente com os agentes comunitários de saúde, deve realizar busca ativa dessas gestantes ${ }^{4}$.

Já a data provável do parto é calculada levandose em consideração a duração média da gestação normal (280 dias ou 40 semanas a partir da data da última menstruação), mediante a utilização de calendário 5 .

No Pré-natal destaca-se a figura do profissional enfermeiro, que participa deste momento desenvolvendo estratégias e processos educativos, por meio de consultas, palestras, e orientações, sanando dúvidas, medos e angústias relacionados ao momento vivenciado pelas gestantes. A equipe de enfermagem durante $\bigcirc$ pré-natal contribui para a promoção de saúde do binômio, por meio de informações, ações educativas e reflexões de experiência da maternidade, mudanças no organismo, adoção de medidas para a manutenção da saúde e de hábitos para solucionar problemas ocasionados pela gestação².

Na saúde pública, o acompanhamento do prénatal de qualidade contribui de forma considerável na minimização de riscos e complicações pré e pós-parto, por meio das consultas periódicas e continuas com $\circ$ enfermeiro, que oferece consultas e assistências com base em conceitos de prevenção, promoção e vigilância da saúde, garantindo o bemestar e qualidade de vida para seu público alvo ${ }^{3}$.

Cada dia mais as gestantes estão aderindo ao prénatal nas ESF, devido à qualidade da assistência prestada pela equipe de saúde, em especial a equipe de enfermagem, estando as gestantes conscientes da importância do pré-natal para a diminuição de índices de mortalidade maternofetal, além de oferecer consultas, exames e todo tipo de assistência gratuitamente. É importante ressaltar que o SUS preconiza dentre seus princípios e diretrizes a integralidade da assistência que é entendida como conjunto articulado e continuo das ações, serviços preventivos e curativos, individuais e coletivos, exigido para cada caso em todos os níveis de complexidade do sistema, e a integralidade na assistência depende primordialmente de quem a pratica, neste caso, o enfermeiro ${ }^{5}$.

O enfermeiro atua de maneira a prevenir, promover e recuperar a saúde do indivíduo e da comunidade, desenvolvendo trabalhos tanto individuais quanto coletivos visando à efetividade da qualidade da assistência e promoção da saúde, garantindo acesso universal aos serviços de saúde, e no caso da gestante não é diferente ${ }^{18}$.

Na consulta de pré-natal, em especial no programa da ESF, o enfermeiro é parte essencial no atendimento e assistência de pré-parto, parto e pós-parto por se tratar de um profissional capacitado para atender as expectativas e necessidades das gestantes neste período de tantas transformações ${ }^{19}$.

Devemos conceituar que de fato a consulta de enfermagem é o ato de consultar ou pedir conselho, é um procedimento que se dá por meio da relação de ajuda e uma situação de aprendizagem entre o cliente no caso a gestante, e o enfermeiro, que busca uma solução para os problemas identificados ${ }^{10}$.

Entretanto para Shimizu; Lima (2009) ${ }^{20}$, a consulta de enfermagem é considerada como um instrumento de extrema importância que tem a finalidade de garantir a extensão e cobertura do pré-natal, por meio de ações preventivas e promocionais as gestantes. Exigindo por parte dos profissionais 
envolvidos conhecimentos técnico-científicos, para compreender as mudanças fisiológicas, emocionais e o momento vivido pelas gestantes e seu modo de vida.

Sendo assim, a consulta de enfermagem no prénatal ganha relações diferentes no que diz respeito à implantação de um atendimento assistencial de forma integral e de qualidade, visando à efetividade na prevenção e recuperação de agravos a saúde 5 .

A consulta de enfermagem para ser eficaz é preciso que obedeça a protocolos, com o objetivo da eficácia do atendimento e obtenção de resultados positivos, para isso as ESF adotam como protocolo o caderno de atenção básica do Ministério da Saúde $(2012)^{13}$, no que está explicito como deve seguir o pré-natal de baixo risco, além do número de consultas que devem ser realizadas e suas frequências, padronização e prescrição de medicamentos, solicitação de exames e procedimentos de enfermagem. Seguindo este caderno o MS propõe ao enfermeiro os seguintes tópicos: orientar as mulheres e seus familiares sobre a importância do pré-natal, amamentação, vacinação e preparo para o parto; realizar consulta de pré-natal de gestação de baixo risco; solicitar exames de rotina e orientar tratamento quando necessário, conforme protocolo de atendimento de serviço; encaminhar gestantes identificadas como risco para o médico; realizar atividades com grupos de gestante; fornecer o cartão da gestante, devidamente atualizado a cada consulta e realizar a coleta de exames citopatológico.

O enfermeiro deve orientar, de modo eficaz a importância do pré-natal para que a gestante em questão possa estar consciente de que deve comparecer nas consultas a fim de garantir uma atenção global e eficaz, podendo prevenir, diagnosticar e tratar precocemente as principais intercorrências e complicações que podem vir a acontecer durante o período gestacional ${ }^{21}$.

Durante as consultas de pré-natal, o enfermeiro deve abordar a sexualidade na gestação com foco primordial, já que a gestante em questão passa por uma série de transformações psicológicas e fisiológicas. Contudo, estas devem saber que a diminuição da libido sexual é comum, mas que a relação sexual em si, não causa danos ao feto e assim, também não causa aborto 5 .

Outros temas devem ser abordados de acordo com o MS (2012) $)^{13}$, como orientar as gestantes a reconhecer sinais e sintomas de alerta que possam ocasionar risco à sua vida e a do seu bebê. Tais como: sangramentos, cefaléia persistente, febre, contrações e perdas vaginais anormais (sangue e líquido amniótico), movimentação fetal diminuída ou a ausência de movimentação, dor abdominal, transtornos visuais, ocorrências clinicas ou cirúrgicas. Nestas situações a gestante deve ser orientada a procurar atendimento médico de urgência.

O pré-natal de baixo risco ofertado pelo SUS visa garantir uma assistência integral, transmitindo a gestante confiança e autonomia durante toda gestação e parto, preparando-a para enfrentar um pós-parto tranquilo. Atualmente, a consulta de enfermagem na rede básica de saúde é realizada de acordo com roteiro estabelecido pelo MS, garantida pela Lei do Exercício Profissional e o Decreto número 94.406-874.

Esta conquista, cujo indicador mais evidente foi marcado no Manual Técnico de Assistência Pré-natal do MS, estabelece que as mulheres que tenham acesso ao serviço de saúde devem ser orientadas sobre os programas, palestras, fisiologia da reprodução, regulação da fertilidade, prevenção de doenças sexualmente transmissíveis ${ }^{2}$.

Durante as consultas de pré-natal o enfermeiro precisa estar atento às necessidades das gestantes e de seus familiares, diagnosticando alterações que possam influenciar de forma negativa o desenvolvimento da gravidez. Não impondo seus conhecimentos técnico/cientifico, nem sua realidade e muito menos desconsiderar a realidade da gestante. Ao desconsiderar experiências, realidade social e financeira da gestante, as orientações e ações educativas do enfermeiro se tornam inúteis.

\section{ANÁLISE DOS DADOS}

Este artigo tem caráter observacional, transversal e análise qualiquantitativa dos dados, onde 
buscamos por meio da percepção das gestantes de diferentes contextos sociais, analisar a consulta de enfermagem durante o pré-natal de baixo risco na Estratégia Saúde da Família (ESF's) Rural, Central e Fraternidade, ambas localizadas na cidade de Itapuranga-Go.

Foi entrevistado um total de 30 gestantes, sendo 10 gestantes em cada ESF. As entrevistas ocorreram após a aprovação do Comitê de Ética do Hospital das Clinicas, com o protocolo de número 51765315.8.0000.5078, durante as consultas de pré-natal no mês de abril de 2016 . Utilizamos como instrumento de coleta de dados um questionário no qual dividimos em alguns eixos temáticos onde procuramos conhecer o perfil das gestantes, dados de sua atual gestação, avaliação da equipe de enfermagem, da consulta de pré-natal e sua percepção quanto ao atendimento de enfermagem na rede básica de saúde. Para caracterizar o público alvo selecionamos algumas variáveis como: idade, nível de escolaridade, estado civil, profissão, renda familiar, número de filhos. Procuramos também conhecer um pouco da atual gestação como: planejamento da gestação, tipo de parto desejado, unidade hospitalar que será realizada e pôr fim a percepção da gestante quanto ao atendimento prestado pela equipe de enfermagem a gestantes.

A análise dos dados foi realizada de acordo com a ordem do questionário, e agrupadas de acordo com semelhanças, onde analisamos as repostas seguindo os objetivos proposto no trabalho. Agrupado os dados de cada unidade separadamente chegamos ao seguinte resultado: $\mathrm{Na}$ ESF fraternidade as gestantes têm idade entre 13 a 27 anos. Um fator importante a ser mencionado é que as mulheres inseridas em um contexto social mais vulnerável, precário, sem recursos financeiros e pouca instrução engravidam muito jovens, como é o caso de grande parte das mulheres que realizam o pré-natal na ESF Fraternidade. Em relação ao estado civil, cinco gestantes estão em união estável, quatro são casadas e apenas uma é solteira. Quanto à renda familiar, nove gestantes relatam ter renda familiar entre 1 e 2 salários mínimo por mês e uma gestante com a renda familiar entre 3 e 4 salários mínimos. $O$ nível de escolaridade está entre o ensino fundamental incompleto ao ensino médio incompleto.
Das entrevistadas, uma atua como domesticas, uma costureira e oito são donas de casa.

Sobre o número de filhos, cinco gestantes referiram ter dois filhos, quatro são primigestas e uma relata ter três filhos. Quando questionadas sobre o planejamento da gravidez, oito delas responderam que não planejaram, e apenas duas planejaram e relataram o desejo de ser mãe. Com relação às semanas de gestação, observamos uma variação entre 18 a 36 semanas de gestação. Quanto ao número de consultas, um critério de inclusão estabelecido para a realização da pesquisa, foi de que as gestantes tenham no mínimo três consultas de enfermagem na referida unidade de saúde e nas três ESF's. Esse critério foi cumprido.

Nesse eixo procuramos tratar dos desejos e planos das gestantes quanto à via de parto, para isso dividimos em duas categorias: parto vaginal e parto cesariano.

Na categoria parto vaginal, nove gestantes relatam sua preferência por esse tipo de parto, devido ao poder aquisitivo baixo, não tendo dinheiro para pagar o parto cesáreo no particular. Todas têm a intenção de realizar o parto no Hospital Municipal de Itapuranga-Go.

A categoria de preferência pelo parto cesáreo contou apenas com uma gestante que alegou como principal razão o medo do parto normal e posteriormente realizar a laqueadura, a mesma relatou ainda que $\circ$ procedimento seja realizado na rede privada (Maternidade Ângela Mares em Itapuranga-Go).

A avaliação da percepção das gestantes referente à qualidade do serviço oferecido no pré-natal é um eixo temático que buscou investigar a satisfação, avaliação e sugestões das gestantes. Foram evidenciadas três categorias: bom, ótimo e excelente.

Na categoria ótimo e excelente, nove gestantes relatam estar contentes com $\circ$ atendimento recebido durante $\circ$ pré-natal, ressaltando alguns pontos de destaque durante as consultas como: acolhimento da equipe de enfermagem que as fazem sentir seguras; auscultar o BCF e informações 
de seu estado de saúde; algumas palestras e a oportunidades de tirar dúvidas quanto ao seu estado fisiológico, emocional e psicológico; realizar exames e receber medicamentos da rede básica de saúde sem custos financeiros. Enquanto que na categoria bom, percebemos que as gestantes estão parcialmente satisfeitas, nesse eixo foi incluída apenas uma gestante. A participante acredita que - pré-natal não contemplou todos os aspectos que deveria. Os pontos de satisfação são os mesmo da primeira categoria, mas os pontos de insatisfação são: pouco tempo de consulta, as consultas rápidas limitam a possiblidade de esclarecer dúvidas e as palestras são escassas e abordam apenas alguns temas, devendo ter mais ao decorrer do pré-natal.

Nesse eixo temático abordamos a avaliação da equipe de enfermagem e da consulta de pré-natal.

Onde nove gestantes relatam que a consulta de enfermagem varia entre ótimo a excelente sentindose seguras com as informações e procedimentos realizados pelos profissionais de enfermagem, todas acreditam que a equipe está preparada para sanar dúvidas relacionadas à saúde da mãe e do bebê. Todas relatam não ter o que reclamar das consultas de pré-natal e também não tem sugestões estando satisfeitas com $\circ$ atendimento e procedimentos realizados. Classificando 0 atendimento de enfermagem com nota 9,8. Apenas uma gestante declarou que $o$ atendimento poderia sofrer algumas melhorias como: redução do tempo de espera para consulta e ter o aumento do número de palestras com diversos temas, atribuindo nota 9,0 para equipe de enfermagem e consulta de enfermagem.

Na ESF Central, as participantes tiveram sua primeira gestação com idade entre 20 a 24 anos. As participantes da pesquisa apresentam idades entre 23 a 32 anos. Das entrevistadas nove são casadas e uma é divorciada. A renda familiar varia entre 3 e 8 salários mínimos, onde nove declaram ter renda entre 3 e 4 salários e uma com renda entre 7 e 8 salários mínimos, e o quanto ao nível de escolaridade percebemos que duas possuem - ensino médio completo e oito ensino superior completo. Quatro atuam como empresarias, uma estudante, duas vendedoras e três dona de casa.
Em relação ao número de filhos e o planejamento da gestação, percebemos que seis gestantes são primigestas e quatro referem ter dois filhos com a atual gestação. Porém apenas uma não planejou a gravidez, mas relatou o desejo e a alegria de ser mãe. Em relação à idade gestacional, nesta unidade existe uma grande variedade, encontrando entre 20 semanas a 32 semanas de gestação.

Quanto à via de parto percebemos que seis gestantes têm a preferência pelo parto cesáreo, alegando a preferência por determinado médico, por considerar o atendimento hospitalar privado melhor e por fim, o medo de sentir dor na hora do parto. Tendo como opção de hospital privado (cinco gestantes na Maternidade Ângela Mares e uma no Hospital Ortopédico de Ceres).

A preferência pelo parto vaginal conta com quatro gestantes, no qual apenas duas pretende realizar o parto na rede pública (HMI - Go), por acreditarem ser um direito, já que pagam todos os seus impostos em dias. E as outras duas gestantes tem a pretensão de terem seus partos na rede privada (Maternidade Ângela Mares), mesmo sendo o parto normal, alegando preferência por um determinado médico. $\mathrm{Em}$ relação à percepção das gestantes quanto à consulta de enfermagem pode ser definida em três categorias: bom, ótimo e excelente. Na categoria ótimo e excelente, oito gestantes consideram que o atendimento nas consultas de pré-natal é satisfatório como os seguintes procedimentos realizados: acolhimento, sinais vitais, ausculta de BCF e palestras. Já na categoria de bom encontramos duas gestantes que afirmam que o pré-natal é bom, mas tem alguns pontos a serem melhorados como: diminuir o tempo de espera para a consulta, ter mais palestras com temas relacionados à gestação.

Como eixo central da pesquisa, abordamos a avaliação da consulta de enfermagem e $\circ$ conhecimento da equipe de enfermagem. Das 10 gestantes, oito se sentem seguras com as informações e procedimentos realizados, acreditando que a equipe de enfermagem está apta, com conhecimentos técnico-cientifico, para sanar dúvidas relacionadas a esse período tão importante da vida de uma mulher. Não tendo nenhuma sugestão ou reclamação. Classificando o atendimento de enfermagem com a nota 9,5 e duas gestantes 
acreditam que atendimento pode melhorar com adição de mais palestras e mais tempo para realização de consultas. Atribuindo nota de 9,0 para a equipe e consulta de enfermagem.

Outra ESF pesquisada é a Rural, onde apresentou uma grande variação na idade das gestantes que encontram entre 18 a 36 anos. Das 10 gestantes, seis são casadas, uma é solteira e três estão em união estável. A renda mensal de nove das participantes varia entre 3 e 4 salários mínimos e uma gestante entre 1 e 2 salários. Quanto ao nível de escolaridade, oito gestantes possuem 0 ensino médio completo e apenas duas tem o ensino superior completo. Das entrevistadas apenas uma tem vínculo empregatício, atuando como secretaria e nove são donas de casa. Em relação ao número de filhos, sete gestantes relatam ter três filhos, duas possuem quatro filhos e apenas uma é primigesta. Com relação à gestação atual se foi ou não planejada, sete gestantes responderam que foi planejada e três não planejaram e relatam que não era hora de engravidar. Esse grupo de gestante encontra com a idade gestacional variando entre 25 a 35 semanas. Quanto aos desejos e planos a via de parto: seis gestantes optaram pelo parto cesariano, devido à realização de laqueadura, ambas serão feitas na rede pública (HMI-Go), e três referem o desejo por parto normal por acreditar ser mais saudável para mãe e bebê, e uma relata que $\circ$ parto normal na rede pública é um direito garantido pela Constituição Federal de 1988.

A percepção das gestantes quanto ao atendimento oferecido pela equipe de enfermagem está centrada em três categorias: bom, ótimo e excelente. Das 10 gestantes atendidas na ESF Rural, oito consideram o atendimento recebido como sendo bom, enquanto que duas relatam que o atendimento é ótimo. Mas todas relatam a necessidade de ter mais palestras para esclarecer e sanar dúvidas relacionadas à gestação.

Já a avaliação da equipe de enfermagem e da consulta de pré-natal, as gestantes relatam que se sentem seguras com as informações e procedimentos realizados, as mesmas acreditam que a equipe tem conhecimento técnico cientifico para atuar e sanar suas dúvidas, classificando o atendimento entre bom e ótimo, e atribuindo nota 9,5 para o atendimento da equipe de enfermagem.

Após analisar os dados das três ESF's separadamente, podemos perceber algumas diferenças no contexto social, econômico e cultural das gestantes. Na ESF Fraternidade observamos que as gestantes possuem poder aquisitivo baixo, pouca idade, com pouca escolaridade e a grande parte das gestantes não tiveram a gestação planejada. Encontrando grande parte das gestantes em união estável. A maioria tem a intenção de realizar seus partos no $\mathrm{HMl}$, e a forma de parto a vaginal alegando a falta de dinheiro. Com isso percebemos a percepção das entrevistadas em acreditar que parto normal é para pobres. Enquanto que nas ESF Central, as gestantes têm poder aquisitivo maior, ocupando cargos de destaque e com idade mais elevadas e com um alto nível de escolaridade. Tendo sua gestação planejada e desejada. Já em relação à via de parto, podemos notar que a maioria desejam o parto cesariano e o restante o parto vaginal, no entanto relatam que $\circ$ parto ocorrerá na rede particular. Já na ESF Rural, as gestantes possuem poder aquisitivo relativamente alto, com idades elevadas, grande número de filhos, mas as mesmas relatam que a gestação foi planejada, já a via de parto será cesariana, devido a intenção de realizar a laqueadura, tanto a cesariana quanto a laqueadura será feita na rede pública de saúde (HMI-GO), lembrando que a laqueadura na rede pública somente é realizada mediante o planejamento familiar cumprindo todos os requisitos.

Em relação à percepção das gestantes quanto à equipe de enfermagem e a consulta de enfermagem, notamos que nas três ESF's todas as gestantes estão satisfeitas tanto com a equipe de enfermagem quanto com a consulta de enfermagem prestada a gestantes de baixo risco, relatando que a equipe de enfermagem está preparada com conhecimentos técnico/científicos para sanar dúvidas, medo e anseios neste período. As participantes relatam que durante a consulta é realizado diversos procedimentos como: acolhimento, avaliação do cartão de vacina, pesagem, avaliação das mamas para amamentação, medida do fundo uterino, ausculta do batimento cardíaco fetal, verificação de sinais vitais e algumas palestras. Além dos profissionais serem educados e a atenciosos. Porém alguns pontos negativos foram levantados pelas 
participantes das três unidades como: poucas palestras e os temas são limitados, as mesmas acreditam que deveria ter mais palestras e de temas variados para auxiliar nessa etapa e por fim relatam que o tempo de espera é exaustivo.
Para finalizar a pesquisa, uma questão objetiva na qual procuramos por meio da percepção da gestante classificar a avaliar a consulta de enfermagem e os conhecimentos técnico/cientifico, com conceito de regular a ótimo. Podemos ver os resultados nos gráficos abaixo:

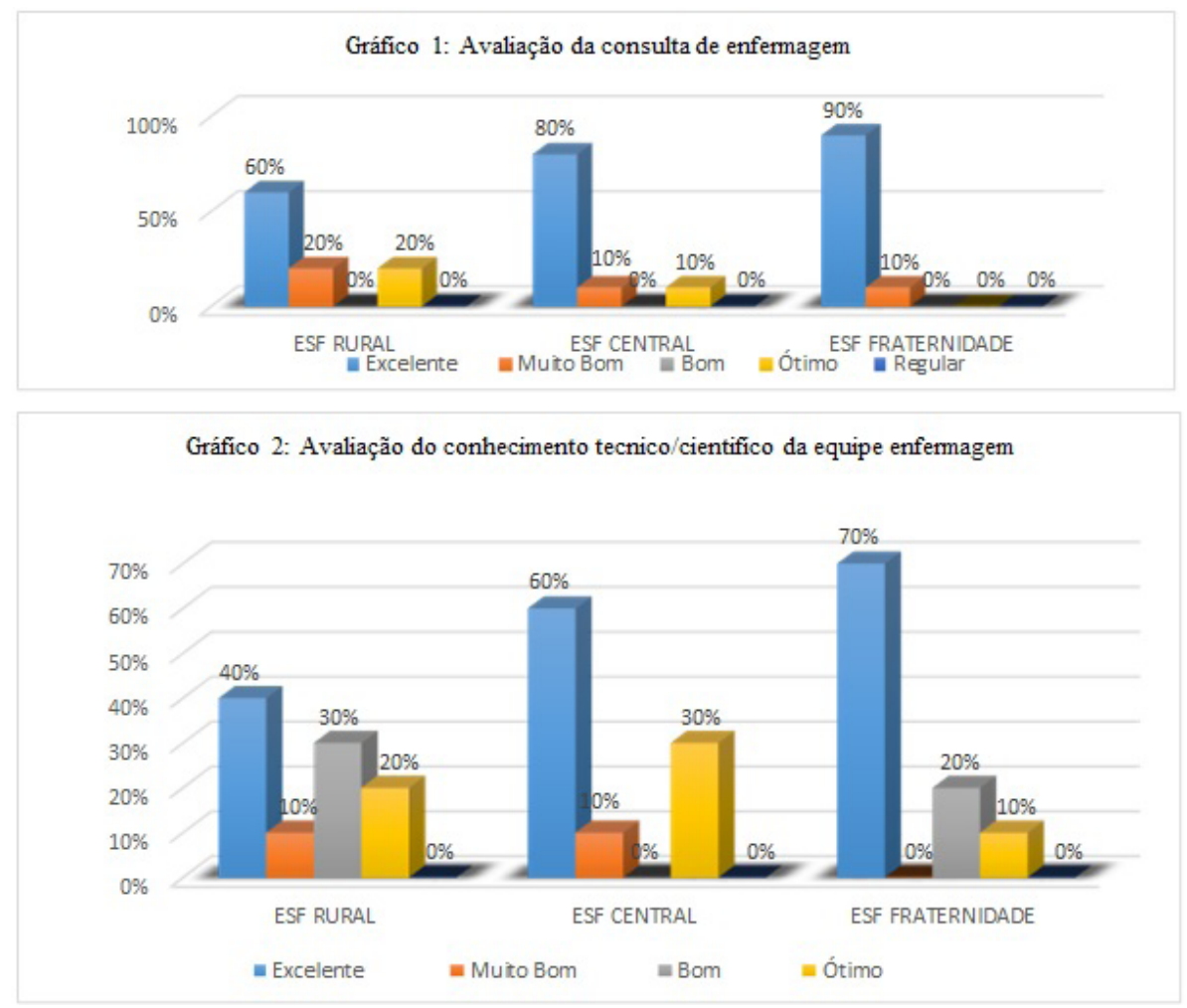

\section{CONSIDERAÇÕES FINAIS}

Este trabalho permitiu analisar o pré-natal em três ESF's em diferentes contextos sociais do município de Itapuranga- GO, por meio de um questionário onde podemos conhecer o perfil das gestantes, suas preferencias, conhecimentos e percepção quanto ao pré-natal de baixo risco ofertado pelo SUS.

Quanto ao perfil da gestante percebemos que na ESF Fraternidade, as gestantes são em sua maioria de baixa renda e menor de idade, não planejaram e nem desejaram ter filhos no momento. A ESF Central concentra as gestantes com maior poder aquisitivo, maior nível de escolaridade e quase todas planejaram a atual gravidez. Enquanto que a ESF Rural possui uma grande variação entre as idades, das 10 pesquisadas apenas uma tem vínculo empregatício enquanto o restante é dona de casa e a maioria planejou a gravidez.
Constatamos que a maioria das gestantes entrevistadas está satisfeitas com $\circ$ atendimento oferecido, reconhecendo que as equipes de enfermagem estão preparadas com conhecimentos técnico/cientifico para atendê-las nesse momento ímpar. As gestantes relataram que em todas as consultas de enfermagem, a enfermeira realiza diversos procedimentos como: pesagem, sinais vitais, medida do AFU, cálculo da idade gestacional, data provável do parto, esclarece duvidas, medos e anseios. No entanto a reclamação geral é a escassez de palestras pertinente à gestação e a espera por atendimento.

Apesar de considerar o pré-natal de qualidade, existe uma falha no que refere ao parto normal, que ainda é considerado por muitas gestantes como um procedimento de pobre, e que os ricos só 
fazem cesariana. Podemos perceber claramente que as gestantes da ESF Fraternidade afirmam que realizará o parto normal no Hospital Municipal de Itapuranga, por falta de recursos financeiros, enquanto que as gestantes da ESF Central tem a intenção de realizar seu parto na rede privada e tem preferência pela cesariana. Já na ESF Rural devido à idade elevada e a quantidade de filhos, grande parte das gestantes pretendem fazer a cesariana e em seguida a laqueadura no Hospital Municipal de Itapuranga. Vale ressaltar que a laqueadura é feita somente mediante ao planejamento familiar.

Diante do exposto percebemos a fragilidade da equipe de enfermagem no que tange ao parto normal, devendo as mesmas realizar atividades com o objetivo de salientar a importância de ambos os partos, pois tanto o parto normal quanto o cesariano possuem objetivos diferentes, cada um possui indicações que devem ser esclarecidas pelo enfermeiro.

Assim concluímos que o trabalho dos enfermeiros no pré-natal ainda enfrenta barreiras, no entanto, o impacto positivo de suas ações durante a gravidez e o parto, bem como o reconhecimento de seu trabalho é evidente e destacado pelas gestantes. Espera-se que as ações desenvolvidas pelos enfermeiros na atenção ao pré-natal possam crescer cada vez mais, atendendo assim as necessidades dessa clientela.

\section{CONFLITOS DE INTERESSES}

Nenhum conflito financeiro, legal ou político envolvendo terceiros (governo, empresas e fundações privadas, etc.) foi declarado para nenhum aspecto do trabalho submetido (incluindo mas não limitandose a subvenções e financiamentos, conselho consultivo, desenho de estudo, preparação de manuscrito, análise estatística, etc).

\section{REFERÊNCIAS}

1. Brasil. Ministério da Saúde. Coordenação de Saúde Materno-Infantil. Programa de Assistência Integral à Saúde da Mulher - Assistência pré-natal. 3. ed. Brasília. DF. 2000

2. Teixeira IR, Amaral RMS, Magalhaes SR. Assistência de enfermagem ao pré-natal: reflexão sobre atuação do enfermeiro para o processo educativo na saúde gestacional da mulher. Revista Cientifica de Departamento de Ciências Biológicas, Ambientais e da Saúde - DCBAS. 2010;3(2):2631

3. Leal DCMF, Monteiro EM, Barbosa MA. Os horizontes da percepção do enfermeiro do PSF sobre os limites de sua legislação. Revista da UFG. 2004;6(especial)

4. Brasil. Ministério da Saúde. Secretaria da Atenção à Saúde. Departamento de Ações Programáticas Estratégicas. Área Técnica de Saúde da Mulher. Pré-Natal e Puerpério: Atenção qualificada e humanizada - Manual técnico. Caderno 5. Brasília. DF. 2006

5. Garcia RAFD. Assistência de Enfermagem no Pré-natal de baixo risco na Estratégia Saúde da Família [Internet]. 2011 [Acessado em 20 de julho de 2016]. Disponível em: http:// www.webartigos.com/artigos/assistencia-de-enfermagem-nopre-natal-de-baixo-risco-na-estrategia-saude-da-familia

6. Oliveira ML, Paula TR, Freitas JB. Evolução Histórica da Assistência de Enfermagem. Conscientia e Saúde. 2007;6(1):127-136

7. Figueiredo NMA, Tonini T. SUS e PSF para Enfermagem: Práticas para o cuidado em Saúde Coletiva. São Caetano do Sul, SP: Gendis; 2007

8. Duarte SHJ, Andrade SM. Assistência pré-natal no Programa Saúde da Família. Escola Anna Nery. 2006; 10(1). doi: $10.1590 / \mathrm{S} 1414-81452006000100016$

9. Narchi NZ. Atenção pré-natal por enfermeiros na Zona Leste da cidade de São Paulo. Rev Esc Enferm USP. 2010;44(2):266-73

10. Garcia SAL, Garcia AS, Lippi UGazi. A necessidade da inserção do enfermeiro obstetra na realização de consultas de pré-natal na rede pública. Einstein. 2010;8(2):241-7. doi: $10.1590 /$ S1679-45082010RW1486

11. Ribeiro JM, Costa NR, Pinto LFS, Silva PLB. Atenção ao Pré-natal na percepção das usuárias do Sistema Único de Saúde: um estudo comparativo. Cad Saúde Pública. 2004; 20(2): 534-45. doi: $10.1590 /$ S0102-311X2004000200022

12. Gonçalves R, Urasakill MBM, Merighi MABarbosa, D'Avila CG. Avaliação da efetividade da assistência pré-natal de uma Unidade de Saúde da Família em um município da Grande São Paulo. Revista Brasileira de Enfermagem. 2008;61(3):349-353. doi: 10.1590/s003471672008000300

13. Brasil. Ministério da Saúde. Secretaria de Atenção à Saúde. Departamento de Atenção Básica. Atenção ao prénatal de baixo risco. Brasília. DF. 2012

14. Costa GD, Cotta RMM, Reis JR, Batista RS, Gomes AP, 
Franceschini SCC. Avaliação do cuidado à saúde da gestante no contexto do programa Saúde da Família. Ciência \& Saúde coletiva. 2009; 1 4(Suppl 1):1347-57

15. Araújo SM, Silva MED, Moraes RC, Alves DS. A Importância do Pré-Natal, a Assistência de Enfermagem. VEREDASFAVIP-Revista Eletrônica de Ciências. 2010;3(2):61 67

16. Filho CG, Filho JVM, Gomes MM, Luquetti AO. Triagem pré-natal ampliada: Teste da mamãe. Vita Et Sanitas, Trindade. 2009;3:101-109

17. Silva APMV, Silva GPSC, Augusto APA, Feitosa FEL. Assistência Pré-natal [Internet]. 2007 [Acessado em 20 de julho de 2016]. Disponível em: http://www.meac.ufc.br/ obstetricia/manual_meac/Docume/pdf

18. Goldman RE. Programa de Saúde da Família: o enfermeiro na atenção a saúde da mulher. Saúde Coletiva. $2007 ; 3(13)$

19. Bezerra CP. A importância da Consulta de Enfermagem no acompanhamento pré-natal. 2009

20. Shimizu HE, Lima MG. As dimensões do cuidado prénatal na consulta de enfermagem. Revista Brasileira de Enfermagem. 2009;62(3):387-392. doi: 10.1590/S003471672009000300009

21. Calderon IMP, Cecatti JG, Veja CEP. Intervenções Benéficas no pré-natal para prevenção da mortalidade materna. Intervenções Benéficas no pré-natal para prevenção da mortalidade materna. Revista Brasileira de Ginecologia e Obstetrícia. 2006;28(5):310-315. doi: 10.1590/S0100$\underline{72032006000500008}$ 